\title{
RECRYSTALLIZATION OF KCL CRYSTALS AFTER PRESSURE INDUCED POLYMORPHIC TRANSFORMATION. TWIN GROWTH, GRAIN BOUNDARY MIGRATION
}

\author{
BORISENKO E. B. and GNESIN B. A. \\ Institute of Solid State Physics, Russian Academy of Sciences, 142432, \\ Chernogolovka, Moscow District, Russia
}

(Received 10 November 1995)

\begin{abstract}
Crystals $\mathrm{KCl}$ as undergone pressure induced polymorphic transformation were investigated. Microstructure and crystallographic orientations of the crystals were studied at once after the pressure removal and as stayed at room temperature for some time. The occurrence of at least six systems of plane defects connected with high pressure treatment at $20 \mathrm{kMPa}$ is found. Their crystallographic indices are determined. It is found that in $\mathrm{KCl}$ crystals after pressure induced polymorphic transformation recrystallization takes place at room temperature. Two stages of recrystallization at room temperature were observed: growth of twins of cubic texture and grain boundary migration.
\end{abstract}

KEY WORDS: Twins, recrystallization, polymorphic transformation, alkali halide crystals.

In alkali halide crystals (AHC) polymorphic transformation (PT) takes place under high pressure: the lattice of type $\mathrm{NaCl}$ (B1) transforms into the lattice of type $\mathrm{CsCl}$ (B2). At removal of pressure, transformation goes in opposite direction, the process corresponds small hysteresis (Livshits et al., 1968; Laukhin et al., 1973). According to (Livshits et al., 1968) direct transformation begins at $19.5 \mathrm{kMPa}$ and is finished at $28 \mathrm{kMPa}$ at room temperature. Linear effect of polymorphic transformation is about $12 \%$.

The interest to unusual increase of mechanical strength of $\mathrm{AHC}$, induced by polymorphic transformation, inspired connectively to application of these materials in laser optics (Balyakin et al., 1992; Valkovskii, 1992). According to (Valkovskii, 1992) the yield stress of $\mathrm{KCl}$ increased from $1-1.5 \mathrm{MPa}$ up to $50-55 \mathrm{MPa}$ in consequence of high pressure treatment at $20 \mathrm{MPa}$. The value of pressure induced strengthening is unusually high for high pure single AHC. However, gradual degradation of mechanical properties of samples, as stayed at room temperature after high pressure treatment, was found out in the same investigation. The causes of hardening induced by phase transition as well as causes of mechanical stress degradation are not clear yet.

\section{TECHNIQUE OF EXPERIMENT}

Single crystals $\mathrm{KCl}$, grown from high pure melt (Valkovskii, 1992), were taken for experiment. Cubic samples faced by $\{100\}$, with rib length close to $8 \mathrm{~mm}$ were put 
into a chamber. The pressure was applied on a technique described in (Livshits et al., 1968). Petrol served as conductive liquid. The crystal was kept for seven minutes at fixed pressure, then pressure was lowered to atmospheric in 30 seconds. Pressure 20 $\pm 0.2 \mathrm{kMPa}$ (once $16 \pm 0.2 \mathrm{kMPa}$ ) was applied to all samples under investigation.

Microstructure was studied by chemical etching, light and scanning electron microscopy. For selective chemical etching two compounds were used: the saturated solution of $\mathrm{PbCl}_{2}$ in ethyl alcohol for revealing of dislocations and $90 \%$ solution of ethylene glycol in water for revealing of large-angle grain boundaries. Microhardness of samples was measured.

Pole figures were obtained by Schultz (tilt) method on automated device. Radiation used was Mo $\mathrm{K} \alpha$, tilt angle varied in a range limited by $75^{\circ}$ (angular steps $\Delta \vartheta=\Delta \varphi$ $=5^{\circ}$ ). Characteristic sizes of irradiated spot on a sample surface were (3-5) $\times$ $(8-16) \mathrm{mm}$. The spot size depends on tilt angle $\vartheta$ and the arrangement of illuminated place depends on rotation $\varphi$. Soller slits on incident and diffracted beams were used. Levels $0.02 ; 0.1 ; 0.4 ; 0.8$ of maximum intensity are reflected on every pole figure. Maximum intensity was corrected with due regard for background and defocusing.

\section{RESULTS AND DISCUSSION}

An etched cleaved surface $\{100\}$ of a crystal at once after removal of pressure is shown on Figure 1a, b. At least, six systems of plane defects, connected with polymorphic transformation, are well manifested. The traces of plane defects belong to different planes. The parallel lines on planes $\{100\}$ lie in directions $\langle 310\rangle$ (Figure 1a), $<210\rangle$ (Figure 1b). For the crystallographic analysis the standard tables of angles between planes and directions for cubic crystals were used (Wassermann, 1962). Accuracy of angle measurements was $2-3^{\circ}$. Figure $1 \mathrm{c}$ illustrates exits of plane defects on face $\{100\}$

(a)

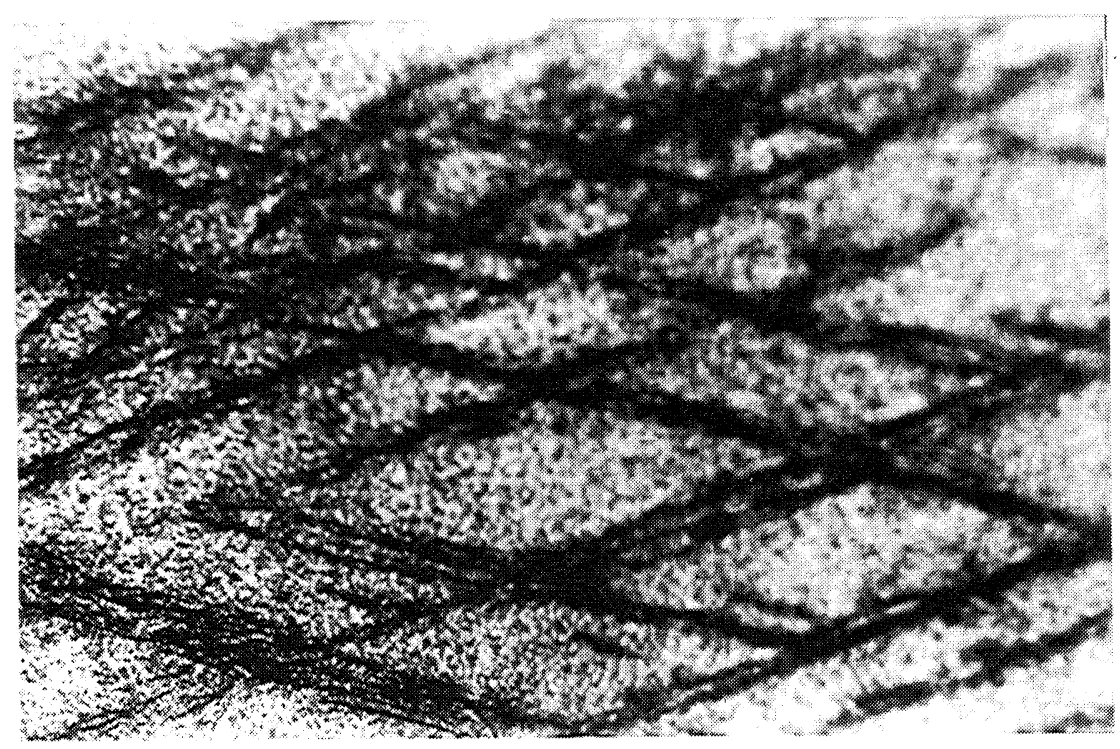


perpendicular to the face shown on Figure 1a, b. Spatial reconstruction (Figure 1d) of mutual arrangement of bands from Figure 1a, b, c shows the planes $\{221\},\{331\}$ to confine the defects. Extend of bands makes in average about 150-200 $\mu \mathrm{m}$. A separate band looks like a package of parallel plates of defects of the thickness about 3-6 $\mu \mathrm{m}$. Average distance between parallel packages of one system was about $20 \mu \mathrm{m}$. The density of the bands determined on casual secants' method was an order of $10^{3} \mathrm{~cm}^{-1}$. Density of these defects is twice less in surface layers of $200 \mu \mathrm{m}$ thickness.

(b)

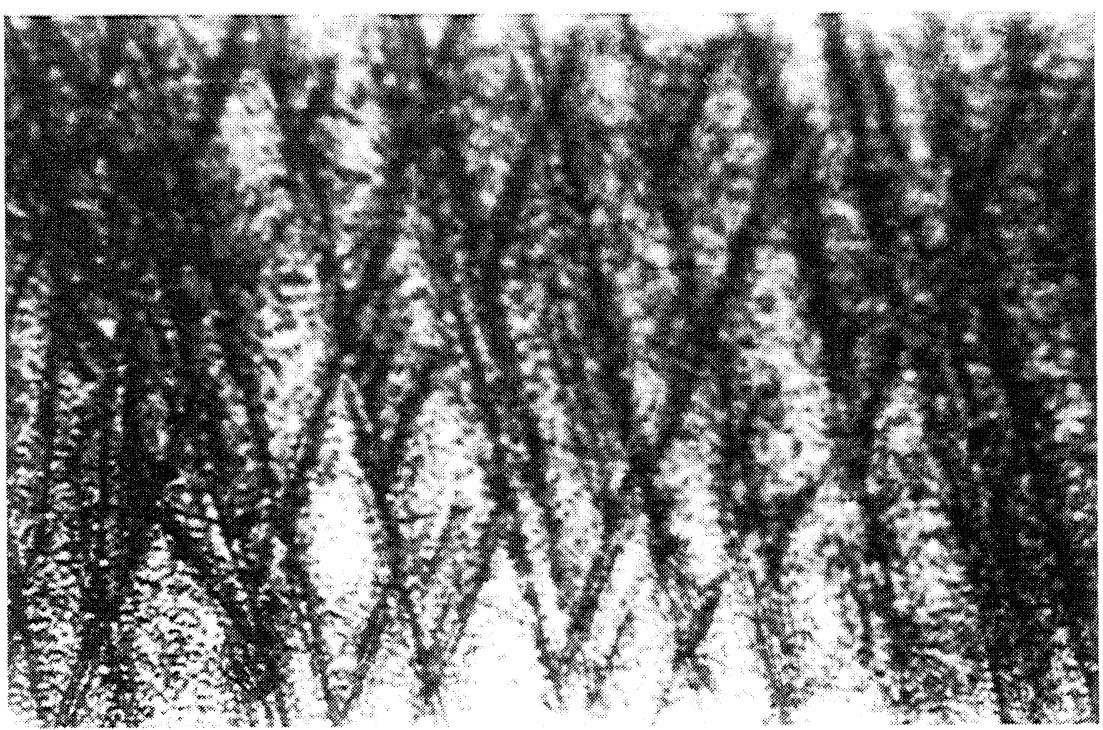

(c)

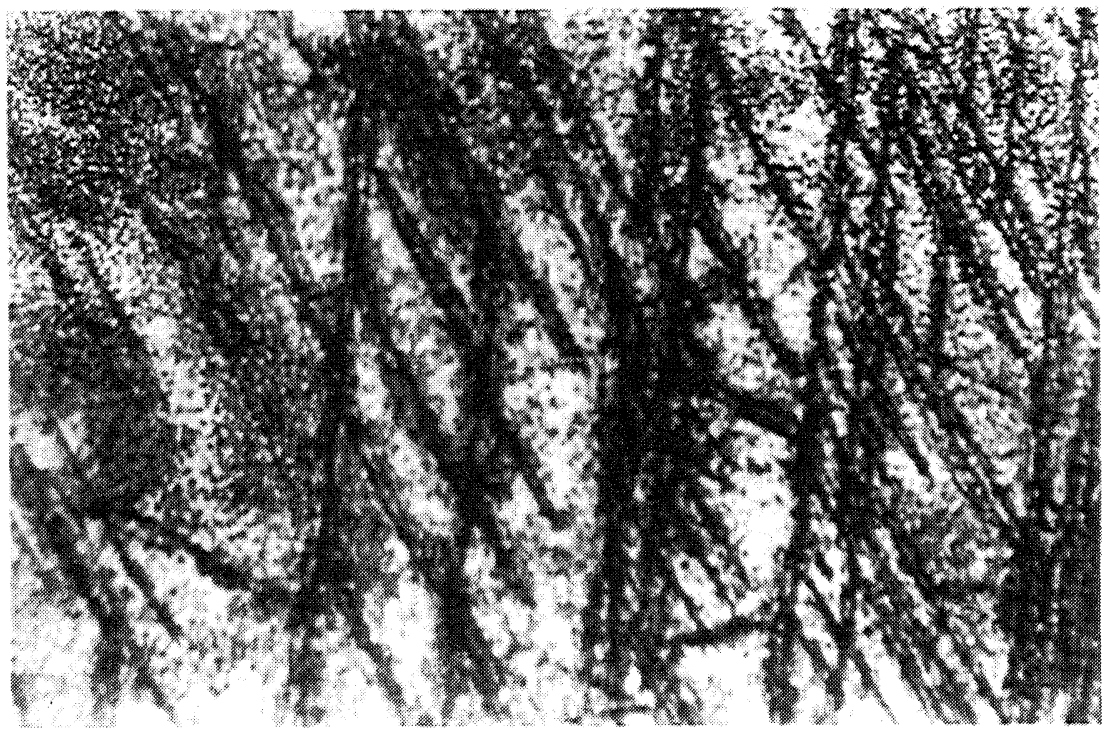


The microstructure of untreated crystal and of crystal after pressure treatment at $16 \mathrm{kMPa}$, i.e. below start point of polymorphic transformation is shown on Figure 1e, f. The treatment at pressure $16 \mathrm{kMPa}$ results only in about 10 times increase of dislocation density. No other changes of microstructure were observed.

(d)

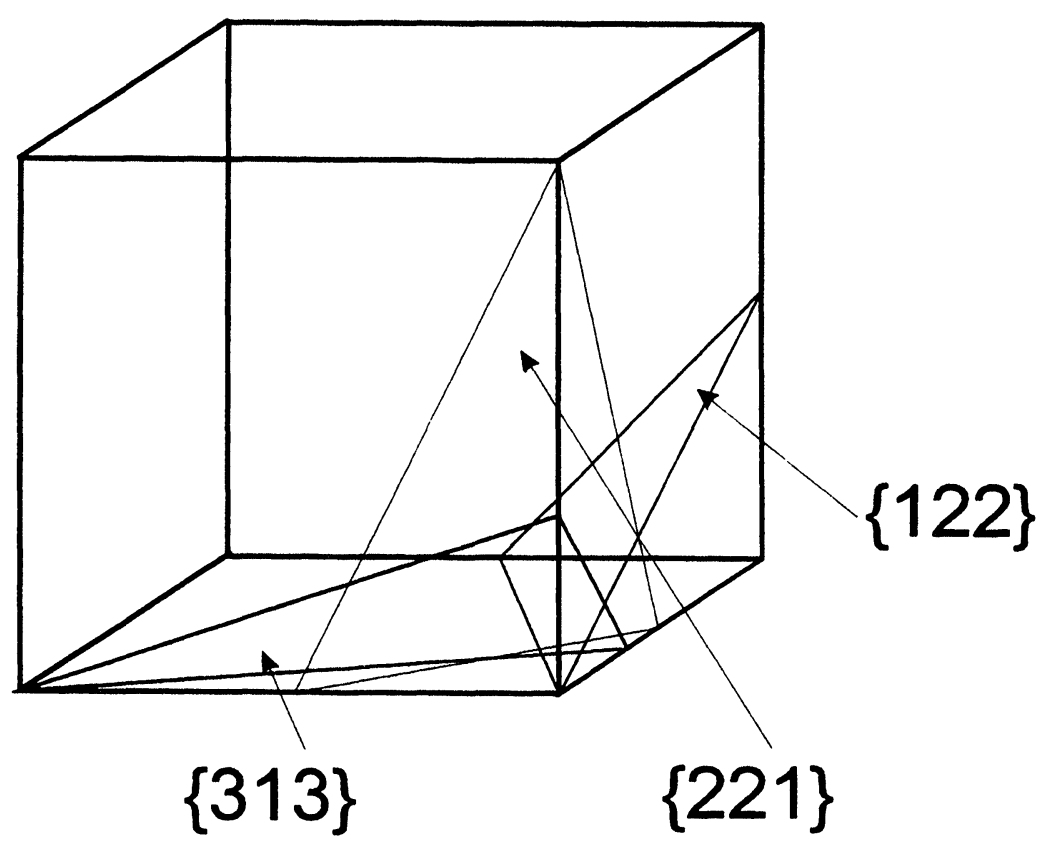

(e)

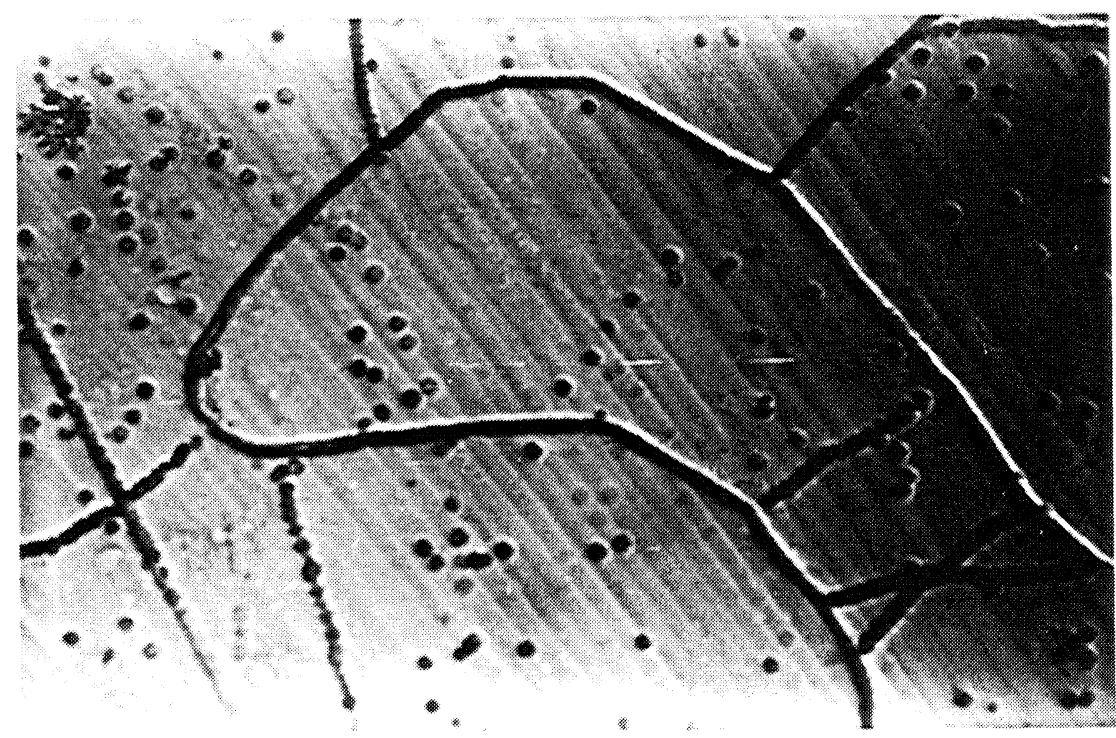




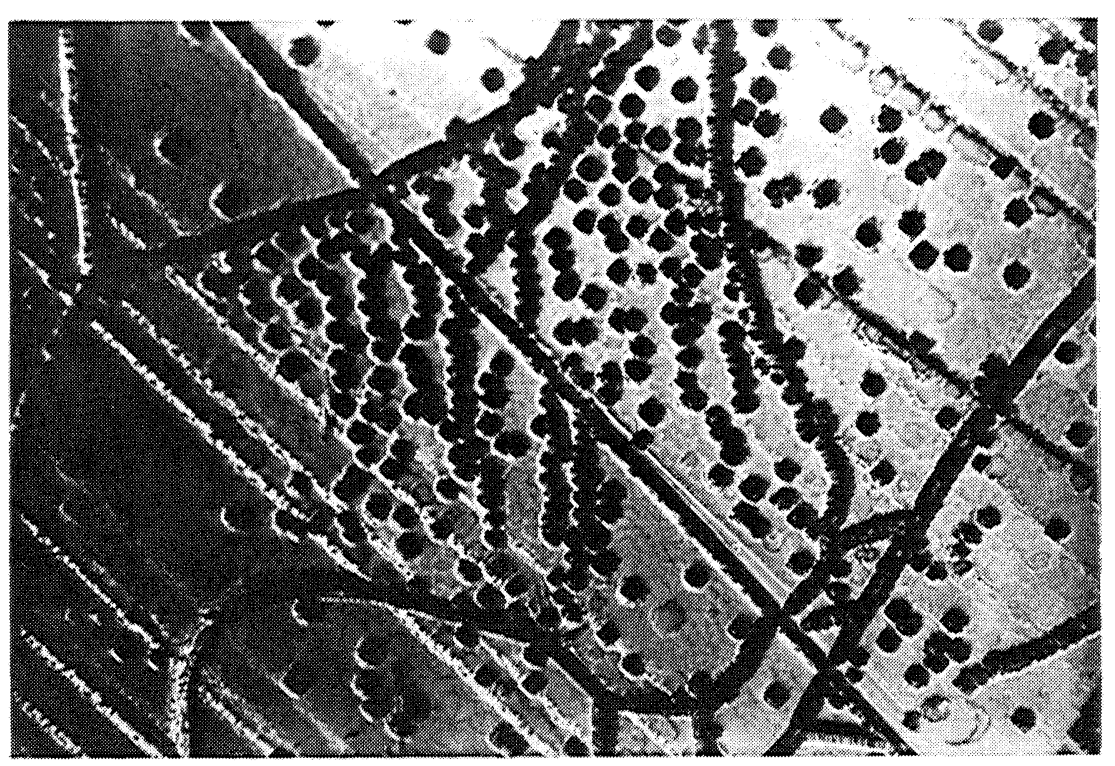

Figure 1 Microstructure of $\mathrm{KCl}$ crystals after pressure induced polymorphic transformation (Figure $1 \mathrm{a}, \mathrm{b}, \mathrm{c}$ are obtained from a sample undergone pressure treatment at $20 \mathrm{kMPa}), \times 200:$ a) bands of defects in $\langle 310\rangle$ directions on a plane $\{100\}$; b) bands of defects in $\langle 210\rangle$ directions on a plane $\{100\} ; c)$ bands of defects on the face perpendicular to that shown on Figure 1a, b; d) spatial arrangement of pressure induced plane defects (scheme); e) microstructure of a sample in the initial state, plane $\{100\}$; f) microstructure after the pressure treatment (applied pressure was $16 \mathrm{kMPa}$ ).

The bands of defects, induced by polymorphic transformation, occupy about $35-40 \%$ of inner area of a sample. According to (Livshits et al., 1968), the volume part of a sample, involved in polymorphic transition at $20 \mathrm{kMPa}$ at room temperature is close to $50 \%$. The difference between these two values may be caused by reversible mostly elastic unloading. The microstructure of a sample after treatment at pressure above start point of the polymorphic transformation is unstable. In a few hours after removal of pressure, areas are manifested in a crystal, obviously distinguished on density of defects and on orientation from surrounding highly defective matrix (Figure 2a, Figure $3 b$ ). In the course of time their participation in microstructure formation increases (Figure 4), their sizes grow to hundreds microns (Figure 2b, c, Figure 3b, c). Evidently, (see Figure 2) grain growth of pressure treated $\mathrm{KCl}$ crystals at room temperature is of unusual kind. On the primary stage of the process, regarded as recrystallization (stage 1 on Figure 4) new grains grow, their boundaries belong to definite directions in the whole, but contain some sites of a kind of a broken line of 3-6 $\mu \mathrm{m}$ lengthways (Figure 2a, b). Such broken lines were observed by light microscopy from the beginning of grain growth. On the 5-7 day boundaries become more smooth and wavy (Figure 2c). This kind of microstructure corresponds to the end of stage 1 of recrystallization (Figure 4). The indices of the straight boundary directions were determined by the above mentioned crystallographic analysis. Accuracy of measurements of angles was about $2-3^{\circ}$. Intersections of grain boundaries with planes $\{100\}$ belong to $<310>,<210>$ directions. 
The facetting of recrystallized grains is visible on crystal fracture (Figure 5a). No obvious distinctions were observed between the center and the edge of a sample. On Figure $5 \mathrm{~b}$ the fracture of the initial crystal, without pressure treatment, is shown.

The variety of grain orientatious observed on Figure $2 a, b, c$, Figure $5 a$ may be seen in the pole figures $\{220\}$ (Figure $3 b, c, d$ ).

(a)

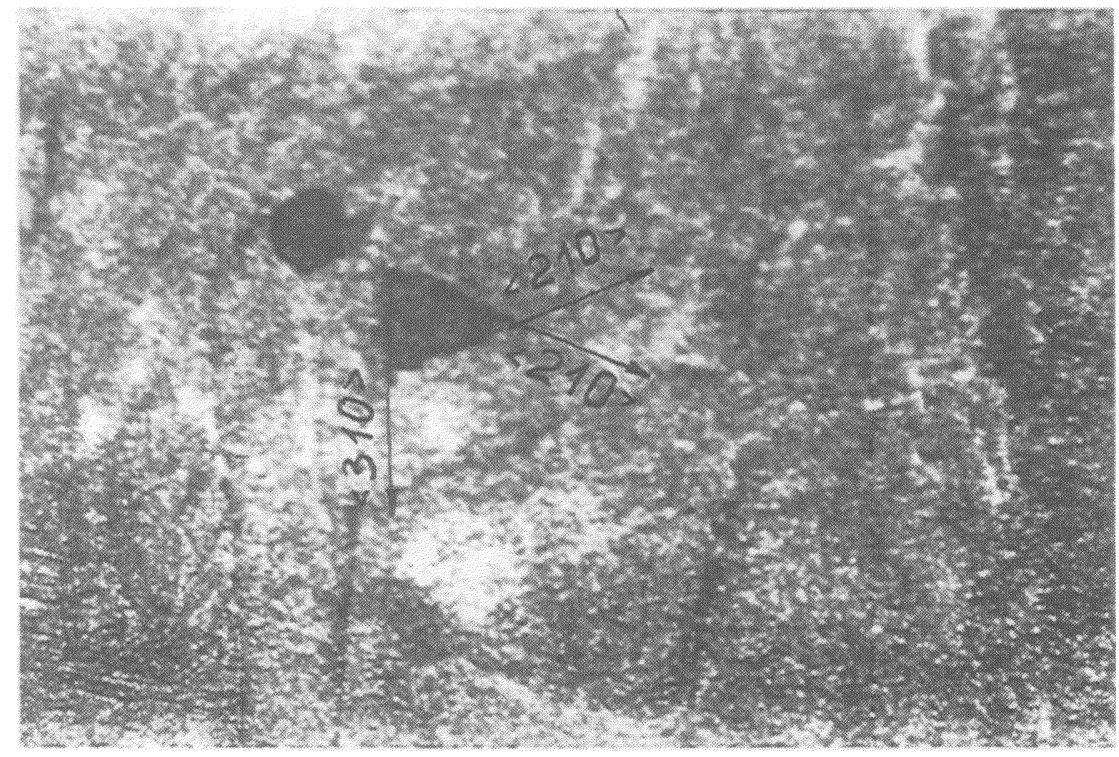

(b)

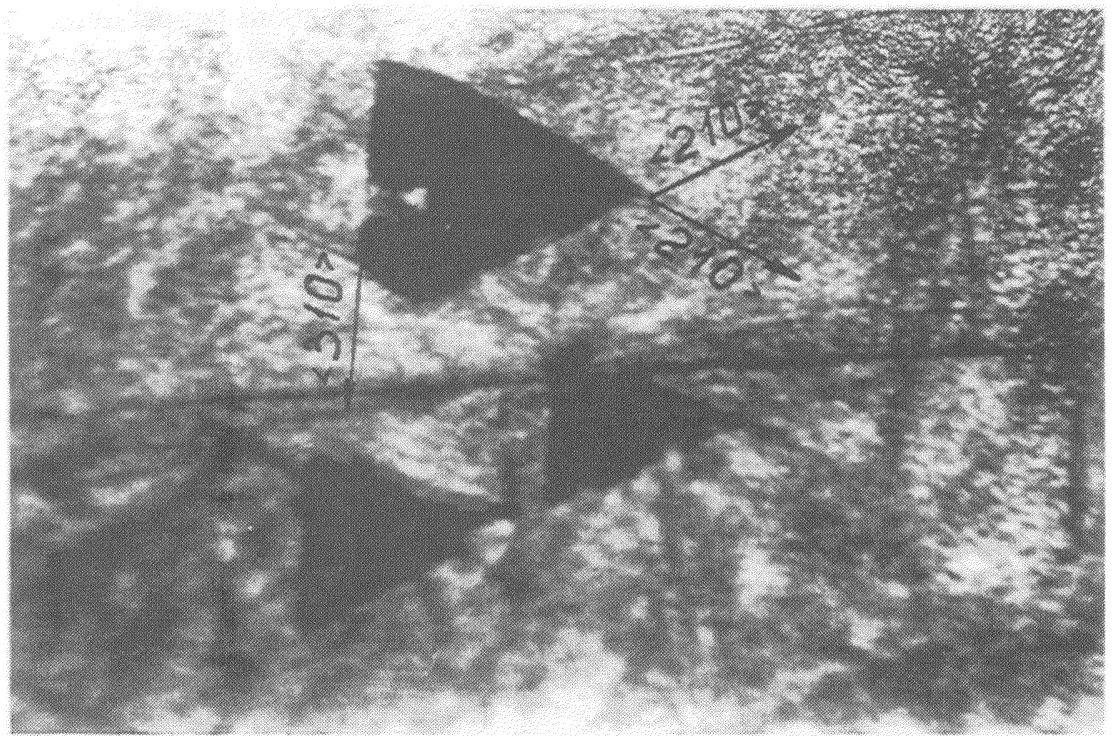




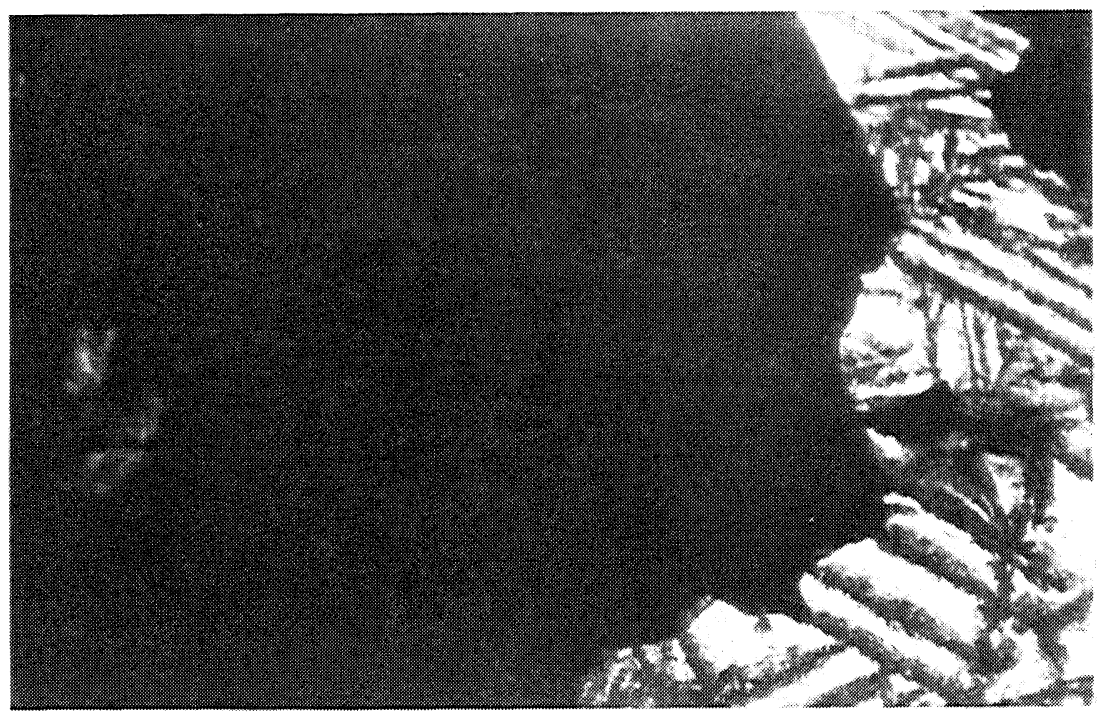

Figure 2 Time dependent changes of the microstructure in $\mathrm{KCl}$ samples as stayed at room temperature after pressure induced polymorphisc transformation, $\times 200$ : a) 1 day b) 3 day; c) 5 days.

Cubic texture, being the characteristic orientation of the initial crystal (Figure 3a), stayed almost unaltered after reversible polymorphic transition (Figure $3 b$ ) for some time after pressure removal. For the time being, some additional maxima of intensity, appropriate to new orientations, appear on the pole figures (Figure 3c). Regretfully, some of the new orientations may not be revealed on the pole figures, for registered intensity of diffraction is obtained from different places on a sample surface for different $\vartheta$ and $\varphi$ angles. Some of new peaks occur to be twins of $\{100\}<001>$ orientation. Cubic texture twins were established on pole figures according to the twin law for B1 structure (twinning plane $\{111\}$ ). This fact was established at comparison of pole figures with stereographic projections of twins of cubic orientation. It becomes evident from Figure $3 a, b, c, d$ that twins occur on the initial period (during 5-7 days) after high pressure treatment.

The twinned orientations $\{112\}<111\rangle,\{133\}<110\rangle,\{013\}<100\rangle,\{012\}<100\rangle$, $\{221\}<112\rangle$ were observed. Grain boundary directions $\langle 310\rangle,\langle 210\rangle$ obtained from etching pictures (Figure $2 \mathrm{a}, \mathrm{b}$ ) belong to twin planes mentioned above. It is necessary to note that the observed facetting of twins is unusual for twins usually observed during deformation and recrystallization. Besides these orientations weak maxima close to $\{335\},\{355\}$ are manifested on pole figures (Figure $3 \mathrm{~b}$ ). The longer is a period after high pressure treatment, the greater is the quantity $\{135\},\{335\},\{355\}$ poles. Noticeable is the fact, that orientations $\{335\},\{355\}$ are no more than $2-4^{\circ}$ declined from twin planes. One more important circumstance comes into notice: the twins of cubic texture and peaks nearby to twins are observed on pole figures so far as poles of initial orientation are obvious. The longer the period after pressure removal, the richer is the spectrum of new grain orientations (Figure 3d). Being kept at room temperature for 
(a)
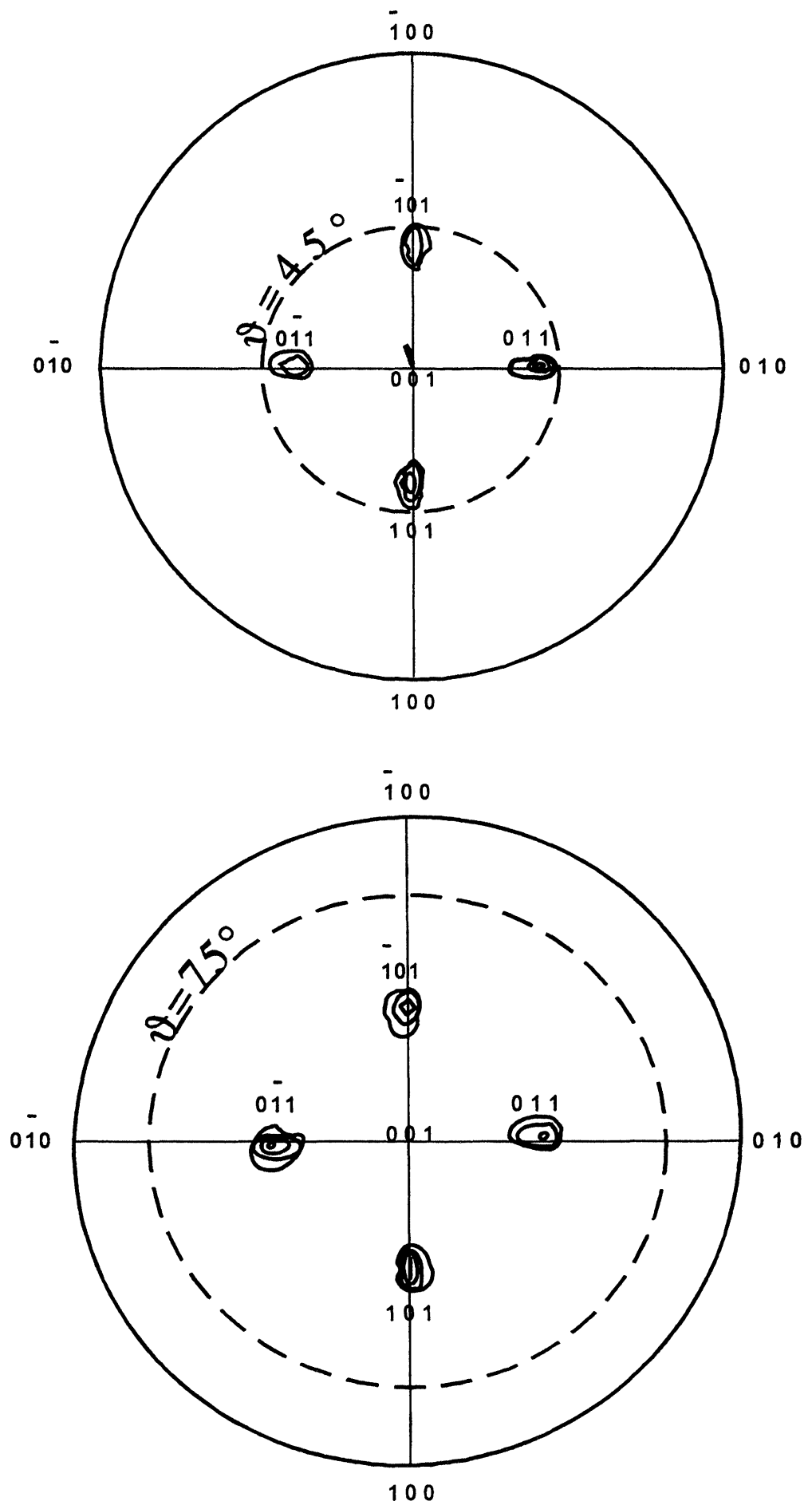

(b) 
(c)
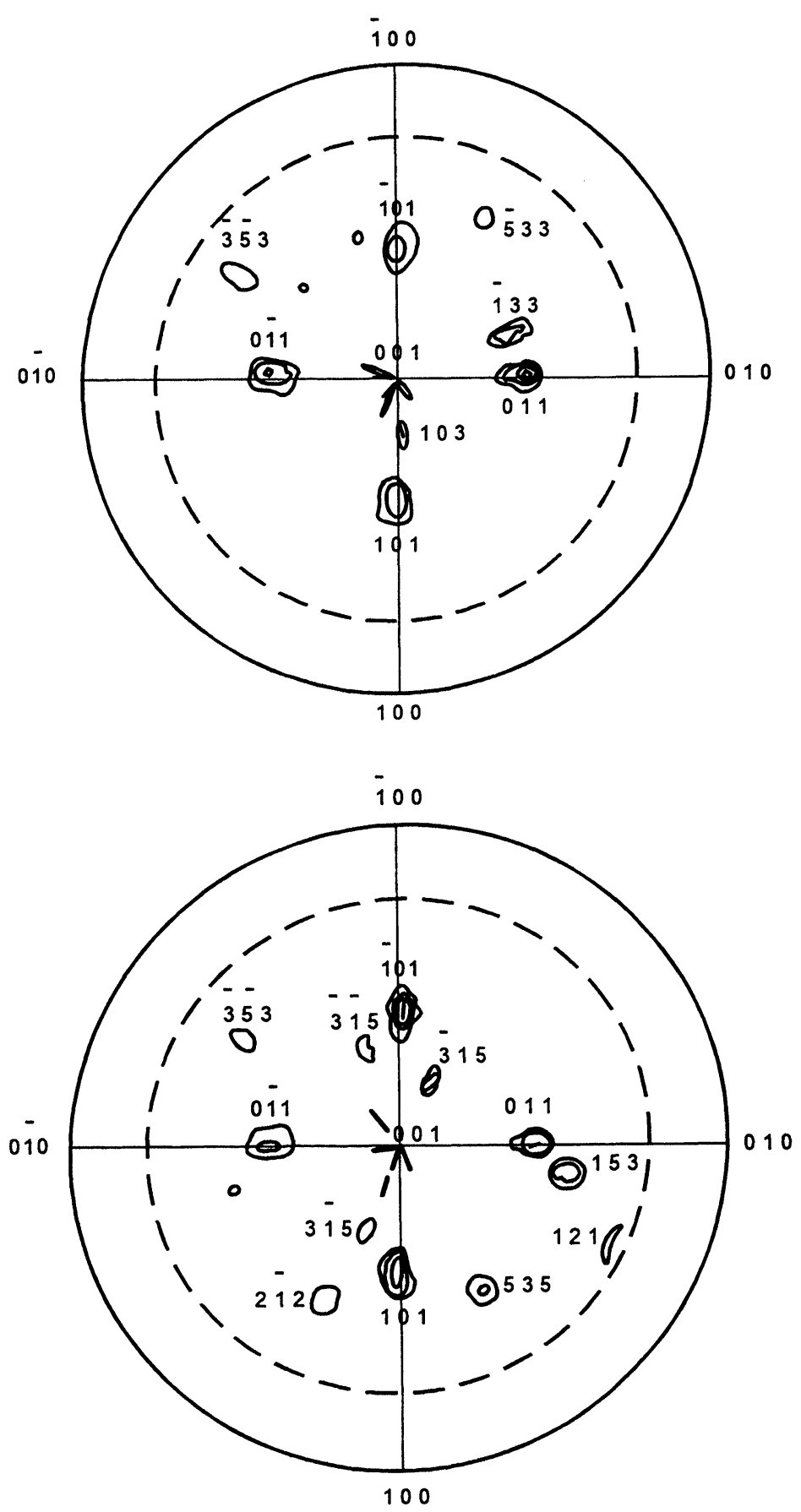

Figure 3 Pole figures $\{220\}$ of $\mathrm{KCl}$ : a) sample in the initial state; b, c, d- a sample after pressure treatment at $20 \mathrm{kMPa}$ and subsequent stay at room temperature for: b) 5 hours; c) 7 days; d) 15 days. 
more than seven days from pressure removal, the samples possess new features of microstructure: the grain boundaries become bent, wavy, grains look like continents with peninsulas (Figure 6).

Kinetics of recrystallization process of $\mathrm{KCl}$ crystals after pressure induced polymorphic transformation is described by Figure 4 . The curve on Figure 4 shows the function of the volume fraction of recrystallized material $\alpha$ on time of a sample held at room temperature after the pressure treatment. Two stages are evident on the kinetic curve. First stage of up to seven days period corresponds to nucleation and growth of facetting grains of twinned orientations (Figure $2 a, b$, Figure $3 b, c$ ). Second stage describes more than seven day period after pressure removal. Grain growth possesses features of usual process of recrystallization on this stage.

The results of microhardness measurements are presented in Table 1. No matter of what stage of recrystallization is on course, the microhardness stays as high as at once after pressure removal until new grains will grow in the highly defective matrix (see Figure $2 b, c$ ). Microhardness of new grains is close to that of untreated crystals (Table 1). The noticeable difference between microhardness of neighbour spots in a sample proved to be a characteristic feature of recrystallization in materials with low stacking fault energy, $\mathrm{KCl}$ being of this kind. Being kept at room temperature for a long time (for three months), after pressure induced phase transformation, the samples possess microstructures, known to be a result of secondary recrystallization. Grains grow up to millimeters in diameter, boundaries become more flat, $120^{\circ}$ junctions form.

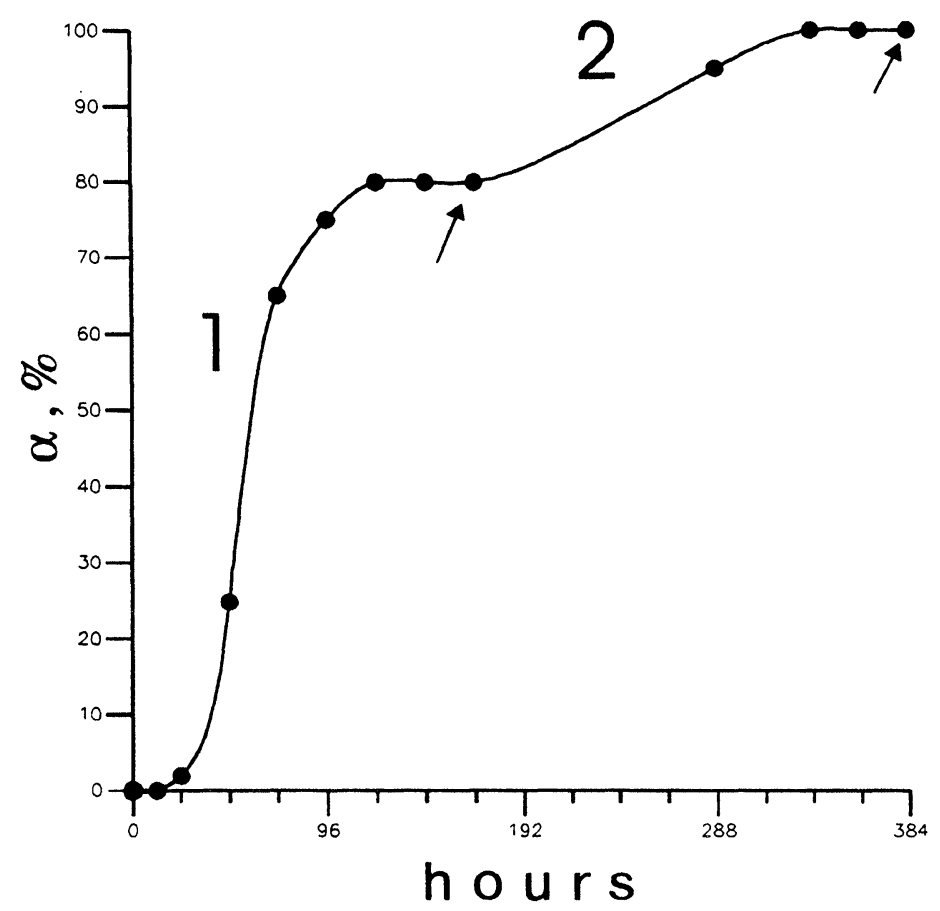

Figure 4 The dependence of the volume fraction of recrystallized $\mathrm{KCl}$ as stayed at room temperature on time (see text for details). 
Table 1 Microhardness of $\mathrm{KCl}$ crystals, $\mathrm{MPa}$

\begin{tabular}{lcccc}
\hline Applied load, $g$ & Initial sample & $\begin{array}{c}\text { At once after pressure } \\
\text { removal }\end{array}$ & $\begin{array}{c}\text { As stayed at room } \\
\text { temperature }\end{array}$ \\
\hline & 175 & 265 & $\begin{array}{c}\text { Defective matrix } \\
20\end{array}$ & New grains \\
\hline
\end{tabular}

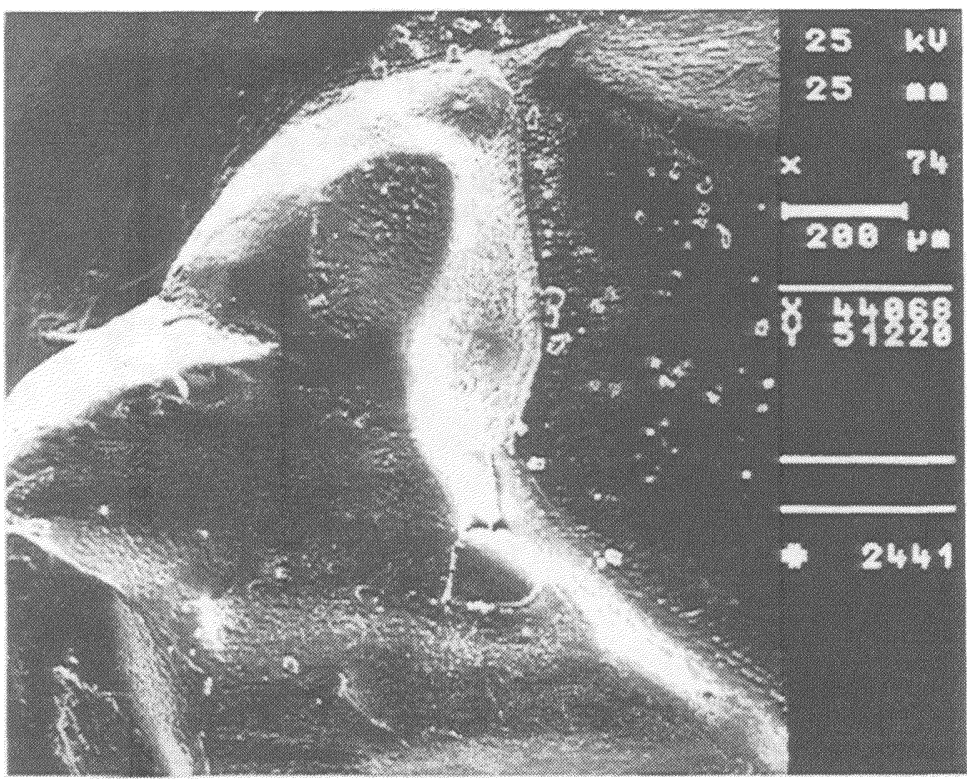

(a)

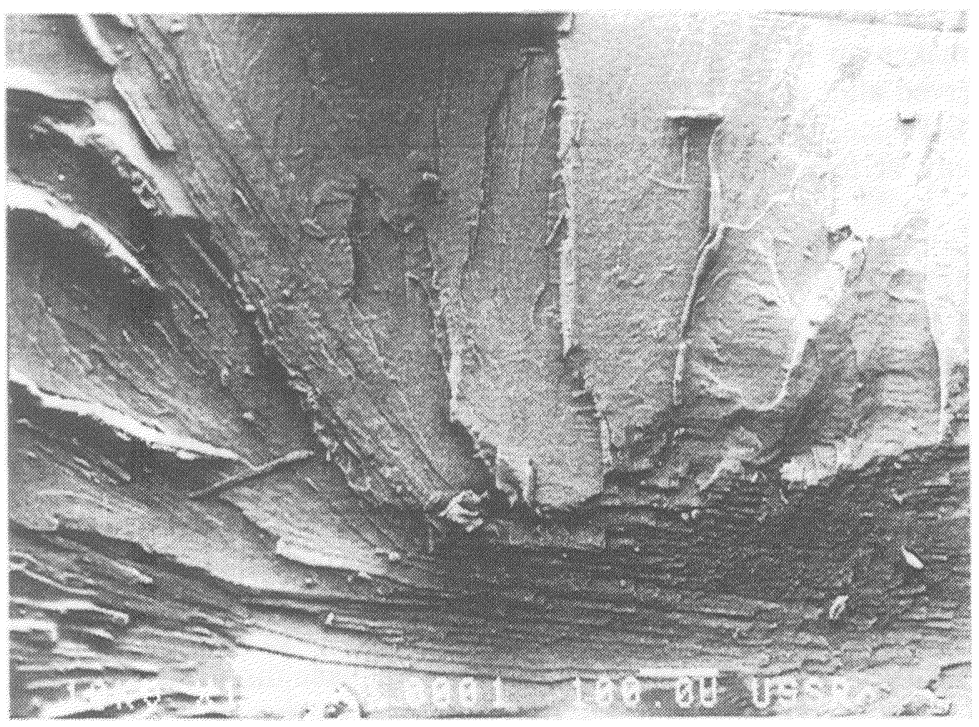

(b)

Figure 5 Fractures of $\mathrm{KCl}$ samples: a) a sample after pressure induced polymorphic transformation and subsequent 7 day stay at rom temperature; b) a sample in the initial state. 


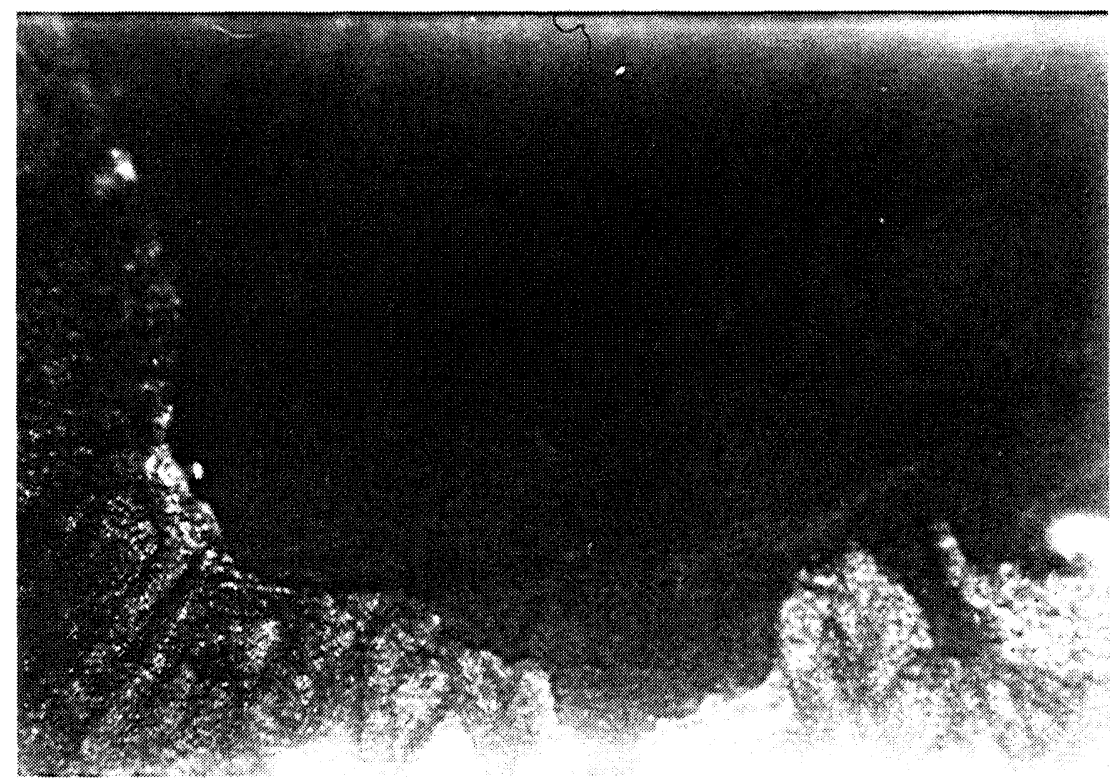

Figure 6 Microstructure of a sample as stayed for 8 days after the pressure treatment at $20 \mathrm{kMPa}$, $\times 200$.

Samples undergone pressure induced polymorphic transformation proved to have another course of recrystallization when annealed at high temperature. The microstructure and pole figure of a sample annealed at $200^{\circ} \mathrm{C}$ for an hour is shown on Figure $7 \mathrm{a}, \mathrm{b}$. In this case an usual course of grain growth is observed. Diameter of grain on Figure $7 \mathrm{a}$ makes up in average about $60 \mu \mathrm{m}$. The cubic texture of the initial crystal is not preserved after annealing, no twins to the initial orientations have been observed (Figure $7 b$ ). Hence, the recrystallization process provided with twin growth may be observed only at temperatures, at least no higher than $200^{\circ} \mathrm{C}$.

\section{DISCUSSION AND CONCLUSIONS}

The questions arise: what are the causes of pressure induced strength increase of AHC and what are the causes of the consequent degradation of improved mechanical properties of crystals as stayed at room temperature after pressure removal.

The shear character of pressure induced phase transition implies the presence of well conjugate planes in latices $\mathrm{B} 1$ and $\mathrm{B} 2$ when the pressure conditions allow the coexistence of both phases. In the considered case no experimental approach is available to determine the orientation relations (OR) between the two phases. We have taken the criterion of plane distances discrepancy for analysis of probable OR (Rozin, 1985): $\delta=$ $\left(d_{1}-d_{2}\right) /\left[\left(d_{1}+d_{2}\right) / 2\right]$, where $d_{1}$ and $d_{2}$ are respectively plane distances between the chosen planes in the phases B1 and B2. The values of lattices parameters taken into account were $\mathrm{a}=6.283 \AA$ (Shaskolskaya, 1982) for $\mathrm{B} 1$ and $\mathrm{a}=3.674 \AA$ for $\mathrm{B} 2$ (Tonkov, 1983). 


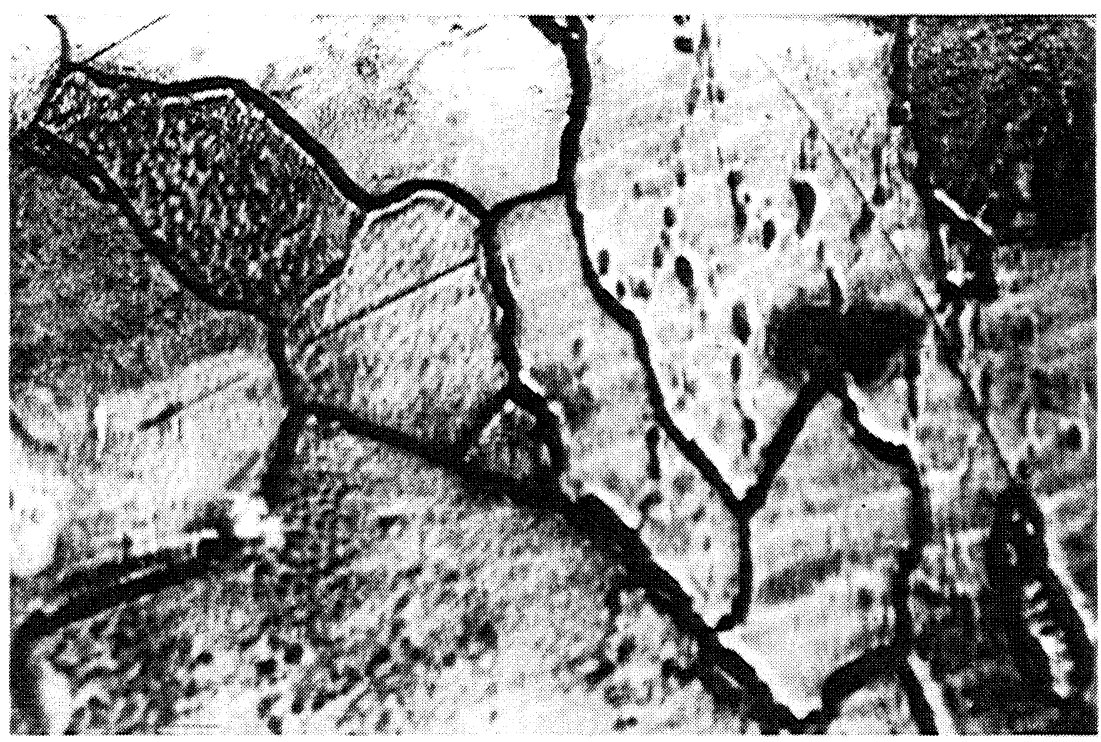

(b)

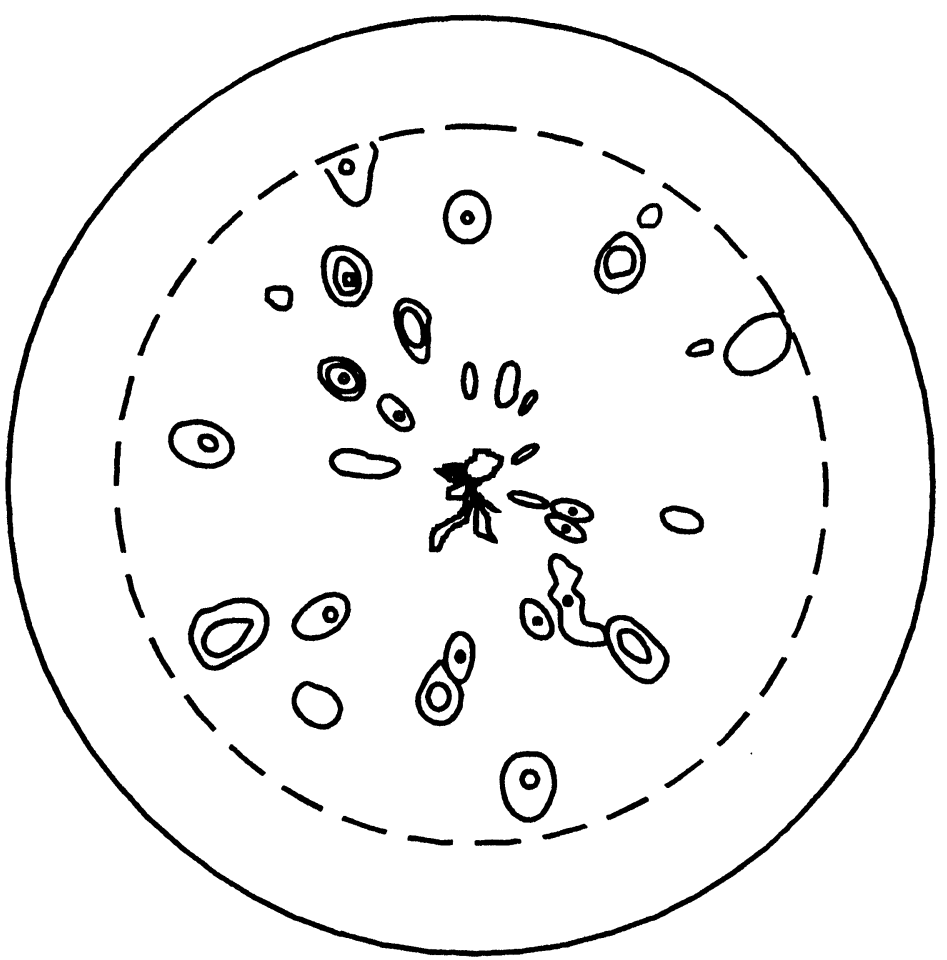

Figure 7 Microstructure (a), $\times 200$, and a pole figure $\{220\}$ (b) of a sample annealed $\left(200^{\circ} \mathrm{C}, 1 \mathrm{~h}\right)$ after the pressure treatment at $20 \mathrm{kMPa}$. 
Received values of relative discrepancy for conjugate planes and directions are presented in Table 2. Obviously, they agree with data on the volume effect of pressure induced polymorphic transformation of $\mathrm{KCl}$ (Livshits et al., 1968). Calculated values of OR are supplied by results of stereographic projections' comparison. Noticeable is the fact that indices of some other planes, namely: $\{221\},\{331\},\{211\}$ coincide in both phases. At availability of OR: (100)[110]B1 \| (110)[001]B2 for both 3-dimension lattices at least four planes of a type $\{331\},\{221\}$ are invariant. In this case it is reasonable to believe that traces of defects in $\langle 310\rangle,\langle 210\rangle$ directions (Figure 1a, b, c) are inherited from interphase boundaries arranged in $\{221\},\{331\}$ planes as shown on Figure 1d.

Detail comprehension of real defective structure in bands of defects (Figure 1) requires further research. On the ground of present work we only have reasons to suggest that there are microtwins, stacking faults, extended dislocation barriers and partial dislocations connected with them, as well as point defects of high density. Distance between partial dislocations (stacking fault width) was estimated. The applied method of calculation is described in (Christian, 1975). In the case of $\mathrm{KCl}$ after pressure induced polymorphic transformation the stacking fault width occurs to be about $700 \AA$ (50 interatomic distances). Spatial mutual arrangement of these defects and their interactions cause the high mechanical strength of pressure treated samples till recrystallization begins.

The yield stress may be regarded as an index of stored energy of a crystal undergone different treatments. The yield stress of $\mathrm{KCl}$ crystals after pressure induced polymorphic transition occurs to be 30 times higher than that one of freshly grown crystal and 2.5 times higher than yield stress of $\mathrm{KCl}$ compressed up to $80 \%$ at $150-200^{\circ} \mathrm{C}$ (Borisenko et al., 1995). Probably, the fact that static recrystallization after pressure induced phase transition begins at lower temperatures than in $\mathrm{KCl}$ samples after high temperature compression may be caused by distinctions in store energy values and in real defective structure in these two cases. Distinctions were observed not only in the kinetics of recrystallization but also in formation of microstructure. At recrystallization following high temperature deformation only grain boundary migration was observed (Borisenko et al., 1995). Recrystallization at room temperature taking place by twin growth proved to be the peculiarity of AHC undergone pressure induced polymorphic transformation.

Nucleation of twins and twin growth may be a profitable mechanism of recrystallization at comparatively low temperatures of materials that possess low stacking fault energy ( $\mathrm{KCl}$ being of that kind). The moving grain boundary separates the new grain, possessing low density of defects, from the highly defective matrix formed at application of high pressure (Figure 2, Table 1). In this sense the process may be regard as recrystallization.

Taking into account the experimental results, we suggest that twins of cubic orientation nucleate and grow in expense of stacking faults of the highly defective matrix (the

Table 2 Orientation relations (OR) of low pressure phase B1 and high pressure phase B2

\begin{tabular}{lc}
\hline Orientation relations $($ OR) & $\delta, \%$ \\
\hline$\{111\}<100>\mathrm{B} 1 \|\{110\}<110>\mathrm{B} 2$ & 14 \\
$\{100\}<110>\mathrm{B} 1 \|\{110\}<001>\mathrm{B} 2$ & 18 \\
$\{100\}<110>\mathrm{B} 1 \|\{110\}<110>\mathrm{B} 2$ & 18 \\
\hline
\end{tabular}


relative part of recrystallized material may be estimated (Figure 4, stage 1) By decrease of defective areas, possessing initial orientation, new grains rose with orientations far from twins of $\{100\}<100>$ (Figure 6, Figure 3d). The course of such grain growth (Figure 4 , stage 2 ) is usual for recrystallization by grain boundary migration.

The possibility of twin growth and subsequent grain boundary migration at room temperature in samples undergone pressure induced polymorphic transformation can be connected with high density and high mobility of point defects in pressure treated crystals and with the formation of large-angle boundaries at the primary stage of recrystallization. Activation energy of point defect migration was, according to (Erofeev et al., 1988), $1.06 \mathrm{eV}$ for the initial crystals and $0.7 \mathrm{eV}$ for $\mathrm{KCl}$ crystals after pressure induced polymorphic transformation.

Hence, degradation of pressure induced high mechanical strength and hardness of $\mathrm{KCl}$ crystals is caused by recrystallization processes going in two stages at room temperature: nucleation and growth of twins and grain boundary migration. There is the basis to believe that the pressure treated samples are mainly softened because of twin growth (see Figure 4, Table 1).

The main experimental results and conclusions are as follows.

1. Six main systems of plane defects connected with pressure induced polymorphic transformation in $\mathrm{KCl}$ crystals were found experimentally. The crystallographic indices of bands of defects were determined. The spatial arrangement of plane defects was realized.

2. Common features and distinctions of recrystallization processes in AHC after high pressure treatment and plastic deformation at high temperatures are found out and described.

3. It was found that in $\mathrm{KCl}$ crystals undergone pressure induced polymorphic transition two stages of recrystallization at room temperature take place. The primary stage is featured by nucleation and growth of unusually facetted twins of initial cubic texture and the second stage proceeds as grain boundary migration.

\section{References}

Balyakin, S. N., Erofeev, V. N. and Peresada, G. I. (1992). The effect of revsersible polymorphic transformation on microstructure and mechanical properties of crystals $\mathrm{KCl}-\mathrm{KBr}$. Solid State Physics, 34, N7, pp. 2063-2068. (in russn.).

Borisenko, E. B., Gnesin, B. A., Lihanova, O. O. and Savchenko, I. B. (1995). Static recrystallization of $\mathrm{KCl}$ crystals deformed at room temperatures. Solid State Physics, 34, N7, pp.2029-2038 (in russn.).

Christian, J. W. (1975). Transformations in Metals and Alloys. Part 1, 3rd edn. Oxford: Pergamon Press.

Erofeev, V. N. and Hartmann, E. (1988). Solid State Ionics, 28-30, pp. 241-244.

Laukhin, V. N., Rabinkin, A. G. and Estrin, E. G. (1973). Phase Transformation in $\mathrm{KCl}$ induced by pressure at low temperatures. Journal of Theoretic and Experimental Physics, 64, N6, pp. 2273-2276. (in russn.).

Livshits, L. D., Ryabinin, Yu. N., Larionov, I. V. and Zverev, A. S. (1968). On the martensite character of the polymorphic transition in $\mathrm{KCl}$ at high pressure. Journal of Theoretic and Experimental Physics, 55, N4(10), pp. 1173-1185. (in russn.).

Rosin, K. M. and Gysev, E. B. (1985). Practical Government on crystallography and crystal chemistry, pp. 152-160. Moscow: Metallurgiya (Metallurgy) (in russn.).

Shaskolskaya, M. P. (1982). In Acoustic crystals, edited by Shaskolskaya, M. P. Moscow: Nauka (Science) (in russn.).

Tonkov, E. Yu. (1983) Phase Diagrams at High Pressure. Moscow: Nauka (Science). (in russn.).

Wassrmann, G. and Grewen, J. (1962). Texturen Metallischer Werkstoffe. Berlin: Springer-Verlag. 